\begin{tabular}{|c|c|c|}
\hline & International Journal of Engineering \& Technology, $7(2)(2018) 742-745$ & \\
\hline & International Journal of Engineering \& Technology & \\
\hline SPC & $\begin{array}{c}\text { Website: } \text { www.sciencepubco.com/index.php/IJET } \\
\text { doi: } 10.14419 / \text { /ijet.v7i2.10410 } \\
\text { Review paper }\end{array}$ & 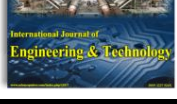 \\
\hline
\end{tabular}

\title{
Impact resistance of sisal fiber reinforced concrete
}

\author{
Y. K. Sabapathy ${ }^{1 *}$, Ramya Sajeevan ${ }^{2}$, J. Rekha ${ }^{3}$, V. Vishal ${ }^{4}$, S. Sabarish ${ }^{5}$, D. Revathy ${ }^{6}$ \\ ${ }^{1}$ Professor, Civil Engineering Department, SSN College of Engineering, Tamil Nadu, India-603110 \\ ${ }^{2}$ Dow Chemicals, Guindy, Tamil Nadu, India- 600032 \\ ${ }^{3}$ L\&T Constructions, Manapakkam, Tamil Nadu, India- 600089 \\ ${ }^{4}$ EPIP Zone, Whitefield, Bangalore, India- 560066 \\ ${ }^{5}$ Undergraduate student, Civil Engineering Department, SSN College of Engineering, Tamil Nadu, India- 603110 \\ ${ }^{6}$ Research Assistant, SSN College of Engineering, Tamil Nadu, India- 603110 \\ *Corresponding author E-mail: sabapathyyk@ssn.edu.in
}

\begin{abstract}
Concrete is typically a brittle material which is prone to damage when subjected to heavy impact loads. To overcome this weakness, concrete is reinforced with fibers as fibers are effective in withstanding heavy impact loads. The main objective of this experimental investigation is to study the influence of sisal fibers in concrete under impact load. The impact specimens are prepared using three grades of concrete- M20, M30 and M40 with five varying percentage of fibers- $0 \%, 0.5 \%, 1 \%, 1.5 \%$ and $2 \%$. The mix designs of the respective grades of concrete are made as per the Indian standards. The specimens after curing for 28 days were subjected to impact loads using the standard drop weight impact machine confining to ASTM standards. Also cube and cylinder specimens are prepared and tested to ascertain the compressive and tensile strength of the sisal fiber reinforced concrete. The results indicated that the sisal fibers are effective in increasing the impact strength of concrete.
\end{abstract}

Keywords: Concrete; Drop- Weight; Fiber; Impact; Sisal.

\section{Introduction}

Fibers in concrete enhance the post-cracking property of concrete thus enhancing the ductility. This increased ductile behaviour is due to the addition of fibers which are capable of transferring the tensile forces across a cracked section effectively thus reducing the crack widths. The extent of crack width reduction depends on the volume of fibers added and the physical properties such as surface roughness, chemical stability and also mechanical properties such as tensile strength, shrinkage and creep, flexural strength, modulus of elasticity [1]. Concrete is subjected to various types of impact conditions which included pile driving, airfield pavements, industrial flooring, protective shelters, hydraulic structures and much more. Concrete materials are subjected to impact loading in various fields of application, including airfield pavements, pile driving, hydraulic structures and industrial floors. Concrete under impact fails extensively because of its brittle nature. Therefore, addition of fibers intensify its many engineering properties such as toughness, flexural strength, impact, resistance to fatigue loads, thermal shocks [2].

Many research studies have been conducted using various types of fibers both natural and artificial since fibers are especially good in taking in the impact loads. Studies show that the fibers are effective in strengthening the concrete's strength such as compression, tensile strength, ductility, and impact [2-5]. Thus the objective of this experimental study is to investigate the influence of the natural sisal fibers in concrete under impact loading conditions.

\section{Experimental program}

To investigate the influence of sisal fibers on the impact strength of concrete was made the primary objective. The impact specimens were prepared for three grades of concrete M20, M30 and M40 for five varying percentages of fibers- $0 \%, 0.5 \%, 1 \%, 1.5 \%$ and $2 \%$ respectively. In total 45 specimens were prepared and tested using standard drop weight impact setup fabricated in accordance with the ASTM standards. Based on the test results conclusions were formulated.

\subsection{Materials and specifications}

Three grade of concrete- M20, M30 and M40 were employed in the preparation of impact specimens as per the IS standards. Cement grade of 43 confining to the standards specified as per IS 8112:1989 [6] was taken as the binding material. Coarse aggregates of size $12 \mathrm{~mm}$ and natural river sand as fine aggregates confining to the specifications of IS 383:1970 [7]. The water-cement ratio was taken as 0.55 . The sisal fibers were added in varying percentages of $0 \%, 0.5 \%, 1 \%, 1.5 \%$ and $2 \%$. Table 1 shows the chemical composition of the sisal fibers used in concrete.

Table 1: Chemical Composition of Sisal Fibers

\begin{tabular}{lll}
\multicolumn{3}{c}{ Table 1: Chemical Composition of Sisal Fibers } \\
\hline & Chemical Composition & \% Present \\
\hline 1. & Cellulose & $67-78$ \\
2. & Hemi- cellulose & $10-14.2$ \\
3. & Lignin & $8-11$ \\
4. & Ash & Nil \\
5. & Pectin & 10 \\
6. & Wax & 2 \\
\hline
\end{tabular}




\subsection{Preparation of the impact specimens}

As per the design mix, the amount of cement, sand and coarse aggregates confining to the IS standards were weighed and the concrete was produced. The sisal fibers were added in varying volume fraction such as $0 \%, 0.5 \%, 1 \%, 1.5 \%$ and $2 \%$. The dimensions of the impact specimens were $64 \mathrm{~mm}$ thick and $150 \mathrm{~mm}$ diameter respectively. 45 specimens for three grades of concreteM20, M30 and M40 were casted with the 5 varying percentages of the sisal fibers and the specimens were cured for 28 days before testing. Figure 1 shows the cured impact specimens.

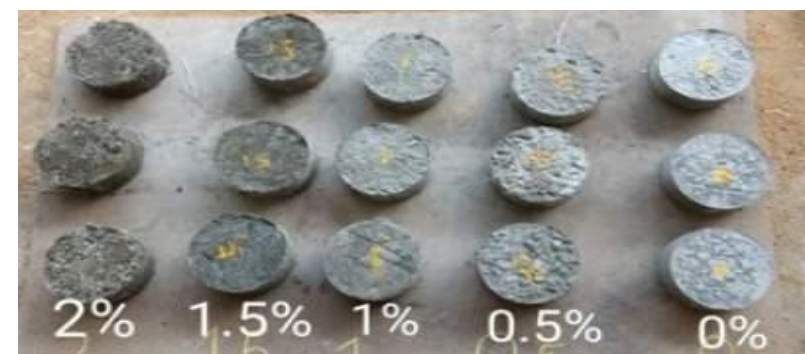

Fig. 1: Cured Sisal Fiber Reinforced Specimens for Impact Testing.

\subsection{Impact test}

The impact resistant test was carried out by using drop weight method recommended by ACI Committee 544-1989 [8]. The drop weight equipment was fabricated according to ASTM standards. The mass and drop height of the manually operated falling hammer were $4.54 \mathrm{~kg}$ and $457 \mathrm{~mm}$ respectively as per ASTM D 1557 [9]. The drop weight test or the repeated impact test is one of the simplest tests carried out to evaluate the energy absorbed by the specimen when subjected to repeated impacts. This test provides the number of blows needed to cause sufficient level of stress in the specimen. The results of the impact test can be used to assess the performance of sisal fiber reinforced concrete under repeated loads [10]. Figure 2 shows the impact setup along with the specimen.

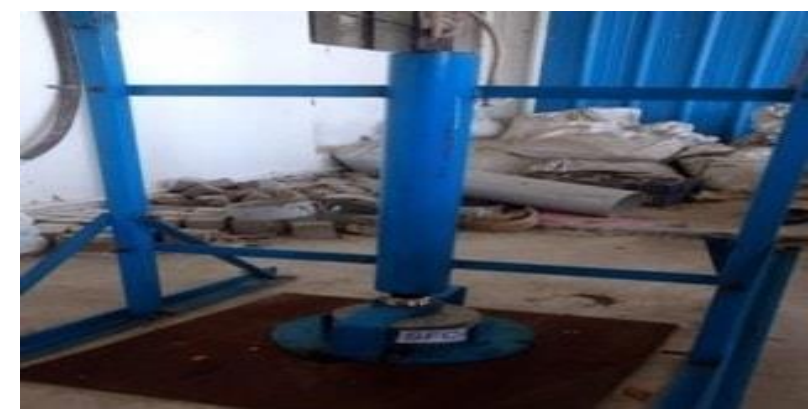

Fig. 2: Impact Test Setup.

The first crack strength is defined as the number of blows for which the first crack on the specimen is visible. The failure strength of the fiber reinforced impact specimen is defined as the number of blows required to generate the 3- lug toughing action. The impact performances of the sisal fiber reinforced specimens were evaluated using three factors: the number of blows required for the first crack; the number of blows required for ultimate failure; the impact strength.

\subsection{Compression test}

Cube specimens of dimensions of $150 \times 150 \times 150 \mathrm{~mm}$ were prepared and tested using the standard compression testing machine with a capacity of $2000 \mathrm{KN}$ confining to IS: 516-1959 [11]. 45 cube specimens were tested with varying volume fraction of fiber $0 \%, 0.5 \%, 1 \%, 1.5 \%$ and $2 \%$ for M20, M30 and M40 grades of concrete respectively.

\subsection{Split tensile test}

The splitting tensile strength test was carried out using the standard Universal Testing Machine with a capacity of $600 \mathrm{kN}$. 45 cylindrical specimens each of size $150 \mathrm{~mm}$ diameter, $300 \mathrm{~mm}$ long were tested with varying fiber volume fraction from $0 \%$ to $2 \%$ for M20, M30 and M40 grades of concrete respectively. The split tensile test was carried out as per IS: 5816-1999 [12].

\section{Results and discussion}

The results of the impact test are shown in table as follows.

\subsection{Impact test}

\subsubsection{First crack strength}

The test result of the average number of blows taken by the impact specimens until the first crack was visible is shown in Table 2. The corresponding values of energy absorbed by the impact specimens for the first crack strength were also calculated.

Table 2: First Crack Strength

\begin{tabular}{|c|c|c|c|c|c|c|}
\hline M20 & & & M30 & & M40 & \\
\hline $\begin{array}{l}\% \text { of } \\
\text { fiber }\end{array}$ & $\begin{array}{l}\text { Avg } \\
\text { no. of } \\
\text { blows }\end{array}$ & $\begin{array}{l}\text { Energy } \\
\text { absorbed } \\
\text { (Joules) }\end{array}$ & $\begin{array}{l}\text { Avg } \\
\text { no. of } \\
\text { blows }\end{array}$ & $\begin{array}{l}\text { Energy } \\
\text { absorbed } \\
\text { (Joules) }\end{array}$ & $\begin{array}{l}\text { Avg } \\
\text { no. of } \\
\text { blows }\end{array}$ & $\begin{array}{l}\text { Energy } \\
\text { absorbed } \\
\text { (Joules) }\end{array}$ \\
\hline 0 & 130 & 2786 & 142 & 2888 & 157 & 3193 \\
\hline 0.5 & 162 & 3417 & 177 & 3600 & 186 & 3783 \\
\hline 1 & 174 & 3539 & 184 & 3742 & 204 & 4047 \\
\hline 1.5 & 187 & 3803 & 217 & 4413 & 243 & 4942 \\
\hline 2 & 212 & 4311 & 228 & 4637 & 259 & 5267 \\
\hline
\end{tabular}

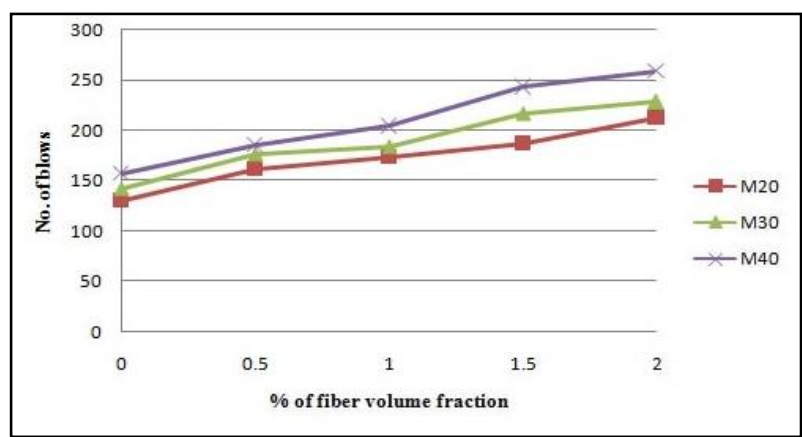

Fig. 3: No. of Blows.

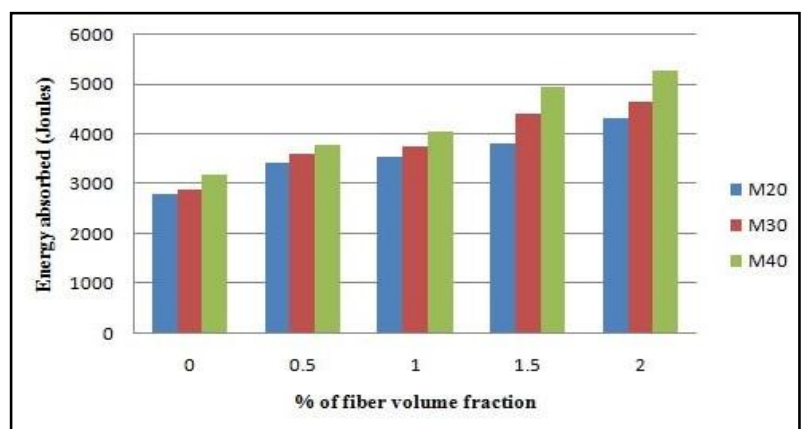

Fig. 4: Energy Absorbed.

Corresponding graphs for the number of blows and the energy absorbed are shown in Figures 3 and 4 respectively. From the figure 3 , the graph shows that the number of blows increased with increase in the percentage of fibers for all the three grades of concrete. This indicates that more the amount of fibers in the concrete matrix, more effective they are withstanding the impact blows. From the energy graph (Figure 4), it can be inferred that the level of energy absorption increased with the increase in volume fraction of fibers. This indicates that the fibers were effective in withstanding the impact load with by absorbing more energy. 


\subsubsection{Impact strength}

The result of the impact strength is tabulated as shown in Table 3.

Table 3: Impact Strength

\begin{tabular}{|c|c|c|c|c|c|c|}
\hline \multicolumn{3}{|l|}{ M20 } & \multicolumn{2}{|l|}{ M30 } & \multicolumn{2}{|l|}{ M40 } \\
\hline & Avg & Impact & Avg & Impact & Avg & Impact \\
\hline $\begin{array}{l}\% \text { or } \\
\text { fiber }\end{array}$ & $\begin{array}{l}\text { no. of } \\
\text { blows }\end{array}$ & $\begin{array}{l}\text { Strength } \\
(\mathrm{Nm})\end{array}$ & $\begin{array}{l}\text { no. of } \\
\text { blows }\end{array}$ & $\begin{array}{l}\text { Strength } \\
(\mathrm{Nm})\end{array}$ & $\begin{array}{l}\text { no. of } \\
\text { blows }\end{array}$ & $\begin{array}{l}\text { Strength } \\
(\mathrm{Nm})\end{array}$ \\
\hline 0 & 154 & 3132 & 166 & 3376 & 175 & 3559 \\
\hline 0.5 & 275 & 5593 & 286 & 5816 & 301 & 6121 \\
\hline 1 & 396 & 8053 & 417 & 8480 & 445 & 9050 \\
\hline 1.5 & 585 & 11897 & 609 & 12385 & 651 & 13239 \\
\hline 2 & 710 & 14439 & 739 & 15029 & 787 & 16005 \\
\hline
\end{tabular}

The average number of blows taken by the impact specimens until the three lug crack is visible which is taken as the impact strength. The corresponding values of impact strength were also calculated and their graphs for the number of blows and the impact strength are shown in Figures 5 and 6 respectively.

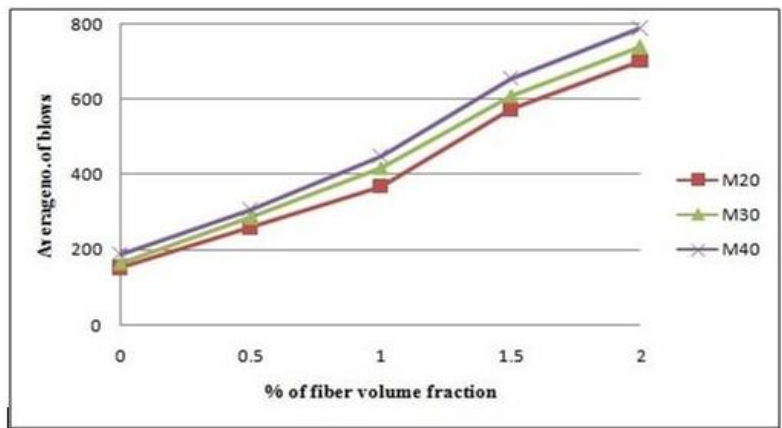

Fig. 5: No. of Blows.

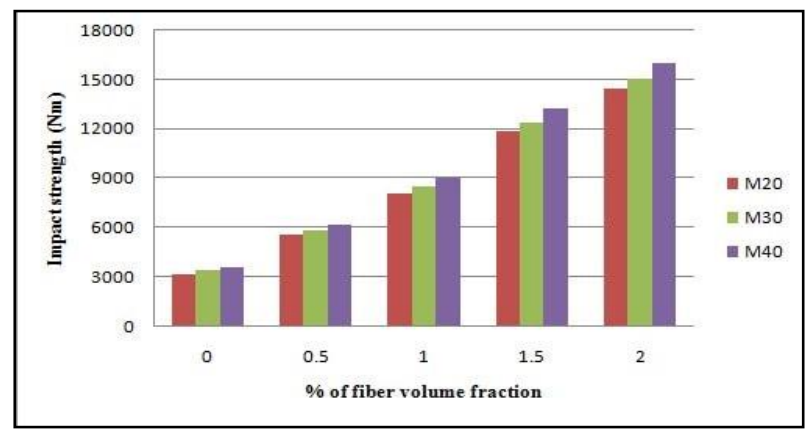

Fig. 6: Impact Strength.

Similar graph patterns are seen for the impact strength as shown in figures 5 and 6 and it can be inferred from the graph that with the increases in the volume of fibers the impact strength increases for all the three grades of concrete. The more the number of fibers, more effective it makes the concrete resolute in withstanding the impact load. Figure 7 shows the tested impact specimens. The crack pattern of the tested specimens was analyzed.

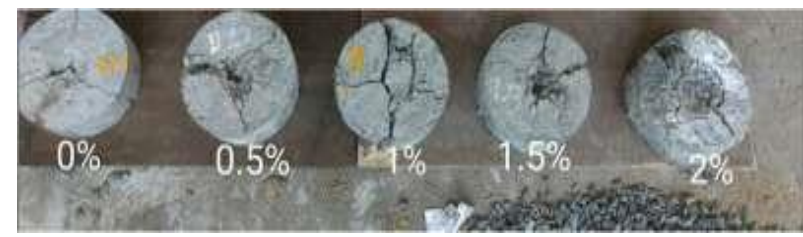

Fig. 7: Tested Impact Specimens.

\subsection{Compression test}

The compressive strength graph is shown in Figure 8.

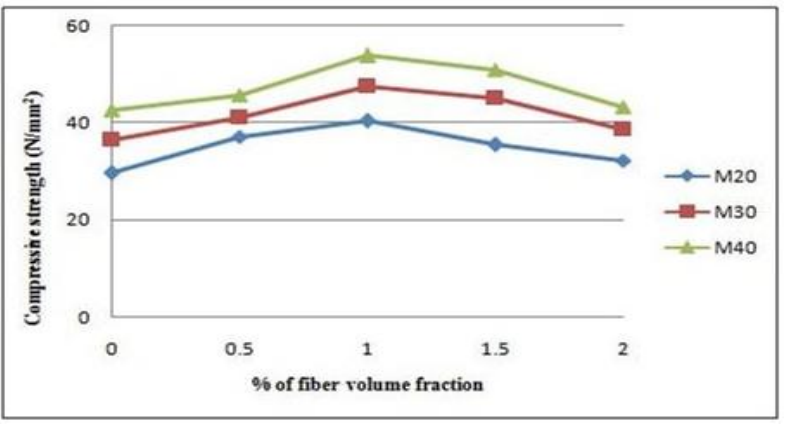

Fig. 8: Compressive Strength.

It can be inferred from the graph that the compressive strength of sisal fiber reinforced concrete peaks at $1 \%$ fiber volume fraction and shows a declination beyond this percentage for all the three grades of concrete specimens tested. This shows that $1 \%$ of fibers are the optimum percentage that can be added to enhance the compressive strength of concrete. Figure 9 shows the tested cube specimens. Upon analyzing the tested specimens only minimal cracks were observed which indicated that the fibers enhanced the compressive strength of concrete significantly.

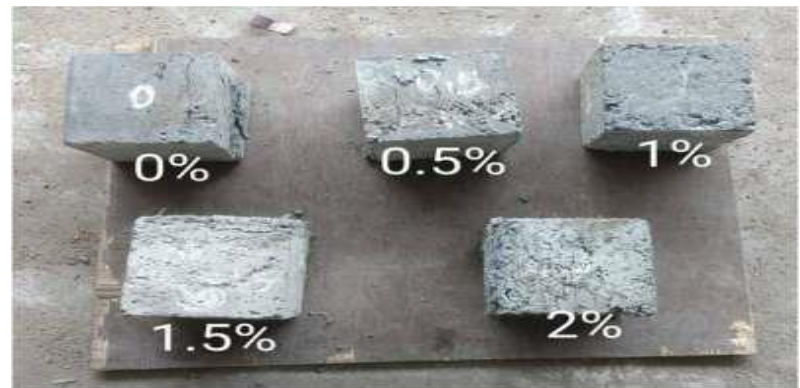

Fig. 9: Tested Cube Specimens.

\subsection{Split tensile test}

The split tensile test values are represented graphically as shown in Figure 10.

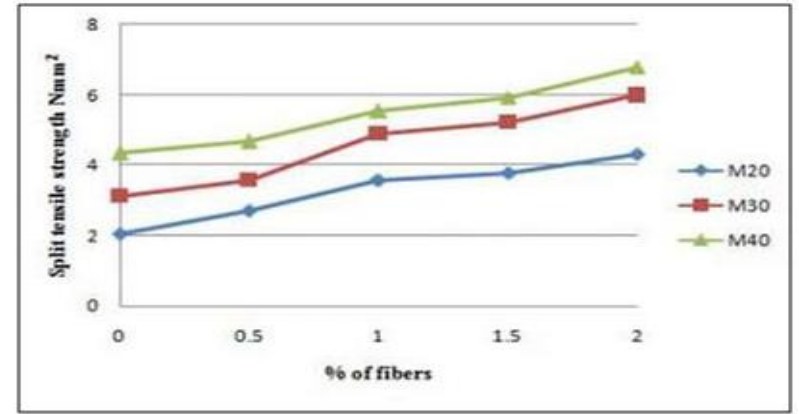

Fig. 10: Split Tensile Strength.

The graph shows a steady rise which indicates that the split tensile strength increases with increase in fiber volume fraction of concrete reinforced with sisal fibers. Figure 11 shows the tested cylindrical specimens. Upon examining the tested cylindrical specimens, only a few cracks were observed and the specimens were not split into two halves when the load is increased. This proves that the fibers were effective in resisting the propagation of cracks.

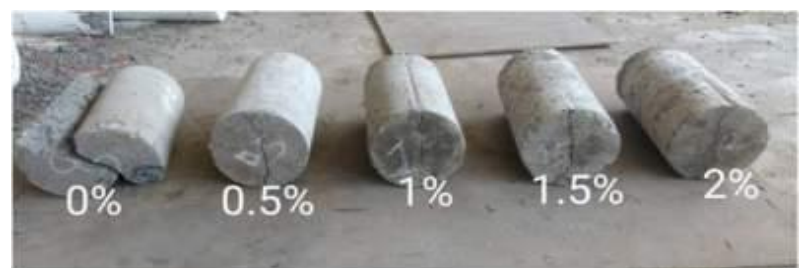

Fig. 11: Tested Split Tensile Specimens. 


\section{Conclusion}

Based on the experimental study the following conclusions are made.

- It was observed that the impact strength of sisal fiber reinforced concrete increases with increase in fiber volume fraction.

- The grade of concrete was found to have a great influence over the impact strength of concrete. As the grade of concrete increases the impact strength also increases.

- The three lug crack pattern was distinct at a lower percentage of fibers. Beyond $1 \%$ the crack patterns were irregular which can be attributed to the presence of higher fiber volume fraction resisting the propagation of cracks.

- $\quad$ The compressive strength of concrete increased upon adding sisal fibers until $1 \%$ for all the different grades of concrete tested in this experimental study.

- The split tensile strength increases with increase in fiber volume fraction indicating the increase in ductility of concrete.

\section{References}

[1] Anette Jansson, "Design methods for fibre-reinforced concrete: a state-of-the-art review", PhD thesis, Goteborg, Chalmers University of Technology, (2008).

[2] Ramadoss P, Nagamani K, "Impact characteristics of high performance steel fiber reinforced concrete under repeated dynamic loading", International Journal of Civil Engineering, Vol.12, No.4, (2013), pp.513- 520.

[3] Aghaee K, Ali Mohammad, "Waste steel wires modified structural lightweight concrete", Materials Research, Vol.17, No.4, (2014), pp.958-966. https://doi.org/10.1590/1516-1439.257413.

[4] Easwara Prasad G La, Keerthi Gowda B S, Velmurugan R, "Comparative study of impact strength characteristics of treated and untreated sisal polyester composites", Procedia Engineering, Vol.17, (2017), pp.778-785. https://doi.org/10.1016/j.proeng.2016.12.096.

[5] Naimathullah Tameen Md, Mohiuddin Y, Haleem M. A, "Experimental investigation of agave fiber on the properties of concrete", Journal of Advances in Science and Technology, Vol.11, No. 22, (2016), pp. 1-7.

[6] Bureau of Indian Standards. IS 8112- 1989. 43 Grade Ordinary Portland cement - Specification. New Delhi: Bureau of Indian Standards; 1989.

[7] Bureau of Indian Standards. IS 383- 1970. Specification for Coarse and Fine Aggregates from Natural Sources for Concrete. New Delhi: Bureau of Indian Standards; 1970.

[8] American Concrete Institute. ACI Committee 544: 1989. Measurement of Properties of Fiber Reinforced Concrete. Michigan: American Concrete Institute; 1989.

[9] ASTM International. ASTM D1557: 12. Standard Test Methods for Laboratory Compaction Characteristics of Using Modified Effort. West Conshohocken: ASTM International; 2012.

[10] Sallam H. E. M, Sherbini A. S, Seleem M. H, Balaha M. M, "Impact resistance of rubberized concrete", Engineering Research Journal, Minoufiya University. Vol.31, No.3, (2008), pp.265- 271.

[11] Bureau of Indian Standards. IS 516-1959. Methods of Tests for Strength of Concrete. New Delhi: Bureau of Indian Standards; 1959.

[12] Bureau of Indian Standards. IS 5816-1999 Splitting Tensile Strength Of Concrete - Method of Test. New Delhi: Bureau of Indian Standards; 1999. 